\title{
Right Cardiac Ventricle Pacing Malfunction
}

National Cancer Institute

\section{Source}

National Cancer Institute. Right Cardiac Ventricle Pacing Malfunction. NCI Thesaurus.

Code C100011.

The cardiac rhythm device malfunction affected the right ventricular (RV) pacing. (ACC) 